\title{
Características quantitativas da carcaça de cordeiros deslanados Morada Nova em função da relação volumoso:concentrado na dieta ${ }^{1}$
}

\author{
Severino Gonzaga Neto ${ }^{2}$, Américo Garcia da Silva Sobrinho ${ }^{3}$, Nívea Maria Brancacci Lopes \\ Zeola $^{4}$, Carlo Aldrovandi Torreão Marques ${ }^{5}$, Aderbal Marcos de Azevedo Silva ${ }^{6}$, José Morais \\ Pereira Filho ${ }^{6}$, Ângela Cristina Dias Ferreira ${ }^{7}$
}

\author{
${ }^{1}$ Parte da tese de Doutorado do primeiro autor apresentada ao Programa de Pós-Graduação em Zootecnia da FCAV/Unesp, Campus de \\ Jaboticabal. Projeto e Bolsa financiados pela Fundação de Amparo à Pesquisa do Estado de SP. \\ 2 Departamento de Zootecnia/CCA/UFPB - 58397-000 - Areia-PB. \\ ${ }^{3}$ Departamento de Zootecnia/FCAV/Unesp - 14884-900 - Jaboticabal, SP. \\ ${ }^{4}$ Doutoranda do Programa de Pós-Graduação em Zootecnia da FCAV/Unesp, Jaboticabal-SP. \\ ${ }^{5}$ Programa de Doutorado Integrado em Zootecnia do CCA/UFPB, Areia-PB. \\ ${ }^{6}$ Departamento de Medicina Veterinária/CSTR/UFCG - 58707-000 - Patos, PB. \\ 7 Unioeste - Presidente Prudente, SP.
}

RESUMO - Com o objetivo de avaliar a influência da relação volumoso:concentrado sobre a composição tecidual e os rendimentos de carcaça e de cortes comerciais de cordeiros Morada Nova em confinamento, utilizaram-se 18 cordeiros com peso vivo (PV) inicial de $15 \mathrm{~kg}$, distribuídos em seis grupos de três animais (um em cada dieta), de acordo com a relação volumoso(V):concentrado(C): 40:60, 55:45 e 70:30. Foram avaliados os pesos de corpo vazio (PCV), de carcaça quente (PCQ) e de carcaça fria (PCF), a partir dos quais foram calculados os rendimentos biológico (RB), de carcaça quente (RCQ) e de carcaça fria (RCF) e a perda de peso por resfriamento (PPR). A carcaça foi dividida em cinco cortes cárneos (perna, lombo, costelas, paleta e pescoço), os quais foram pesados para cálculo de seus rendimentos em relação ao peso da meia-carcaça. A perna foi dissecada em músculo, osso e gordura e os pesos desses tecidos foram expressos em peso absoluto e em porcentagem da perna Calcularam-se as relações músculo:osso e músculo:gordura, o índice de musculosidade da perna (IMP) e a área de olho-de-lombo (AOL). O aumento de 30 para $60 \%$ de concentrado na dieta elevou os rendimentos de carcaça quente e carcaça fria, assim como o rendimento biológico. Os crescentes teores de concentrado na dieta não afetaram a porcentagem de músculo na perna, mas proporcionaram maior deposição de gordura e maior área de olho-de-lombo.

Palavras-chave: área de olho-de-lombo, carcaça, composição tecidual, índice de musculosidade, ovinos, rendimento de cortes

\section{Quantitative characteristics of the carcass of Morada Nova lambs fed different dietary ratios of forage and concentrate}

\footnotetext{
ABSTRACT - Eighteen lambs averaging initial body weight (BW) of $15 \mathrm{~kg}$ were allotted to six groups of three animals (one lamb per diet) and were fed diets with following forage:concentrate ratios (F:C): 1) 40F:60C; 2) 55F:45C; or 3) 70F:30C Lambs of each group were slaughtered when the animal fed the diet with the highest concentrate level reached $25 \mathrm{~kg}$ of BW. Animals were slaughtered after $16 \mathrm{~h}$ of fasting (feed and water). After obtaining the slaughter body weight (SBW), animals were anesthetized by electric discharge and killed by bleeding of the carotid arteries and jugular veins. Blood was then collected and weigthed. Soon after evisceration, skin, head and extremities of the fore and rear members were removed. The gastrointestinal tract (GIT) was emptied, weighted and the value added to that of blood to obtain the empty body weight (EBW), which was calculated by subtracting SBW from GIT + blood weights. The carcasses were weighted and stored at $4^{\circ} \mathrm{C}$ within a 24-hours period. The empty body (EBW), hot carcass $(\mathrm{HCW})$ and cold carcass weights $(\mathrm{CCW})$ were all used to calculate the biological (BY), hot carcass (HCY) and cold carcass yields (CCY) as well as the weight loss by cooling process (CWL). The carcass was divided in five cuts (leg, loin, ribs, shoulder clod and neck) that were weighted for calculation of cut yields. The leg was dissected in muscle, bone and fat, and weights of these tissues were expressed in absolute weight and in percentage of leg weight. The muscle:bone and muscle:fat ratios, index of leg muscularity (ILM) and the loin eye area (LEA) were also calculated. Increasing dietary concentrate from 30 to $60 \%$ increased not only hot and cold carcass yields but also biological yield. The increasing levels of concentrate in the diet showed no effect on the percentage of leg muscle. However, it was observed an increase in both fat deposition and rib eye area.
}

Key Words: carcass, cut yields, loin eye area, muscularity, sheep, tissue composition 


\section{Introdução}

Os ovinos compõem uma espécie doméstica de grande importância nas regiões tropicais, contribuindo largamente para a oferta de alimentos, emprego rural e produtos de uso doméstico, o que eleva seu valor econômico em regiões áridas, semi-áridas e montanhosas e, muitas vezes, em terras marginais e pouco agricultáveis.

A demanda por carne ovina nos últimos anos tem proporcionado crescimento da ovinocultura em várias regiões do mundo. Este fato, associado à maior eficiência de produção e comercialização do produto, possibilita a oferta de carne de qualidade, de animais jovens, com quantidades adequadas de músculo e gordura na carcaça (Kempster et al., 1987). No entanto, os sistemas tradicionais de produção não são suficientes para abastecer esse mercado, haja vista o reduzido emprego de tecnologias e o uso de raças e/ou grupos não apropriados para as regiões de exploração.

A nutrição adequada é importante em qualquer sistema de produção, constituindo o ponto crítico, dentro dos aspectos econômicos, principalmente quando envolve a produção em confinamento. A relação volumoso:concentrado na dieta e a qualidade do volumoso são fundamentais na terminação de cordeiros, pois maiores proporções de volumoso de boa qualidade, invariavelmente, resultam em dietas de menor custo, desde que as necessidades nutricionais dos animais sejam atendidas.

É importante ressaltar que a espécie ovina possui raças específicas, como as lanadas exóticas e as deslanadas nativas, as quais utilizam de modos diferenciados as dietas disponíveis, em virtude do hábito alimentar, das exigências nutricionais específicas e das eficiências de utilização dos nutrientes, cabendo aos pesquisadores investigar a relação volumoso:concentrado mais econômica e mais adequada. Silva et al. (2000) observaram que cordeiros deslanados Santa Inês foram mais seletivos ao material fibroso da dieta que os mestiços lanados Ideal x Ile de France.

O desempenho e as características da carcaça são influenciados diretamente pela composição nutricional da dieta. Entretanto, o maior custo de produção de cordeiros para abate é decorrente da alimentação. Atualmente, buscam-se alternativas para diminuir este custo variável, sem prejudicar a qualidade da carcaça, e aumentar a rentabilidade do sistema. Silva et al. (2003) constataram diferenças na concentração de gordura no corpo de cordeiros recebendo diferentes relações volumoso:concentrado (40:60, 60:40 e 80:20), observando valores médios de 23,53;18,69 e $16,49 \%$ para os lanados e de 17,$35 ; 14,01$ e $13,08 \%$ para os deslanados.
Os poucos trabalhos realizados com a raça Morada Nova, principalmente sobre alimentação suplementar, produção e qualidade da carcaça, são incipientes, deixando grande lacuna aos anseios dos produtores interessados pela raça. Com este estudo, objetivou-se avaliar os efeitos de diferentes relações volumoso:concentrado (70:30, 55:45 e 40:60\%) sobre a composição tecidual e os rendimentos de carcaça e de cortes comerciais de cordeiros Morada Nova em confinamento.

\section{Material e Métodos}

Este experimento foi desenvolvido no Setor de Ovinocultura do Departamento de Zootecnia da Faculdade de Ciências Agrárias e Veterinárias, FCAV/Unesp, campus de Jaboticabal, SP, localizado a $21^{\circ} 15^{\prime} 22^{\prime \prime}$ de latitude sul e $48^{\circ} 18^{\prime} 58^{\prime \prime}$ de longitude oeste, a $595 \mathrm{~m}$ de altitude.

Foram utilizados 18 cordeiros não-castrados, com peso vivo inicial de $15 \mathrm{~kg} \mathrm{e} 70 \pm 5$ dias de idade, distribuídos em três tratamentos, de acordo com a relação volumoso:concentrado (V:C) na dieta: 40:60, 55:45 e 70:30.

Os animais foram identificados e alojados individualmente, até $\mathrm{o}$ abate, em gaiolas de madeira $\left(1,0 \mathrm{~m}^{2}\right)$, com piso ripado suspenso, equipadas com comedouro e bebedouro, distribuídas em galpão com piso de concreto e coberto com telhas de zinco.

Foram realizadas análises laboratoriais para determinação da composição bromatológica das dietas experimentais (Tabela 1). A dieta com menor relação $\mathrm{V}: \mathrm{C}$ foi balanceada para atender às exigências de proteína, energia metabolizável e minerais, segundo o AFRC (1993), para um ganho esperado de $150 \mathrm{~g} / \mathrm{dia}$. As demais foram formuladas com aumento na relação volumoso:concentrado, visando promover restrição qualitativa da dieta e, assim, atender ao planejamento de um ensaio de exigências nutricionais que precedeu este experimento.

As dietas foram oferecidas à vontade, em duas refeições diárias, às 7 e $16 \mathrm{~h}$. Determinou-se o consumo total de MS, por meio do controle diário das quantidades de alimento fornecido e das sobras, encontrando-se valores médios de 539, 614 e $792 \mathrm{~g} /$ dia, para as dietas com relações volumoso:concentrado de 70:30, $55: 45$ e 40:60, respectivamente.

As pesagens dos cordeiros foram realizadas a cada 14 dias, com a finalidade de monitorar o desenvolvimento ponderal dos animais. Para garantir o peso de abate determinado, os intervalos de pesagens foram reduzidos à medida que os animais alimentados com a dieta com maior porcentagem de concentrado se aproximavam dos $25 \mathrm{~kg}$ de PV.

Os animais, nos três tratamentos, foram abatidos quando aqueles que recebiam a dieta com maior porcentagem de 
Tabela 1 - Composição das dietas experimentais, de acordo com a relação volumoso:concentrado $(\mathrm{V}: \mathrm{C})$, com base na matéria seca (MS)

Table 1 - Ingredient and chemical compositions of the experimental diets with different forage $(F)$ :concentrate $(C)$ ratios, on dry matter (DM) basis

\begin{tabular}{|c|c|c|c|}
\hline \multirow[t]{2}{*}{$\begin{array}{l}\text { Parâmetro } \\
\text { Item }\end{array}$} & \multicolumn{3}{|c|}{$\begin{array}{c}\text { Relação } \mathrm{V}: \mathrm{C} \\
F: \text { C ratio }\end{array}$} \\
\hline & $40: 60$ & $55: 45$ & $70: 30$ \\
\hline \multicolumn{4}{|l|}{$\begin{array}{l}\text { Composição percentual }(\% D M) \\
\text { Percent composition (\%MS) }\end{array}$} \\
\hline $\begin{array}{l}\text { Feno de braquiária (Brachiaria hay) } \\
\text { Concentrado (Concentrate) } \\
\text { Milho moído (Ground corn) } \\
\text { Farelo de soja (Soybean meal) } \\
\text { Sal iodado (Iodized salt) } \\
\text { Núcleo mineral (Mineral mix)* }\end{array}$ & $\begin{array}{r}40,00 \\
60,00 \\
32,56 \\
26,74 \\
0,37 \\
0,33\end{array}$ & $\begin{array}{r}55,00 \\
45,00 \\
24,42 \\
20,06 \\
0,27 \\
0,25\end{array}$ & $\begin{array}{r}70,00 \\
30,00 \\
16,28 \\
13,37 \\
0,18 \\
0,17\end{array}$ \\
\hline \multicolumn{4}{|l|}{$\begin{array}{l}\text { Composição bromatológica (MS) } \\
\text { Chemical composition (DM) }\end{array}$} \\
\hline $\begin{array}{l}\text { MS }(D M),(\%) \\
\mathrm{PB}(C P),(\%) \\
\text { EM }(\mathrm{kcal} / \mathrm{kg} \mathrm{MS}) \\
M E(k c a l / k g D M)\end{array}$ & $\begin{array}{r}88,73 \\
17,82 \\
2,34\end{array}$ & $\begin{array}{r}89,34 \\
14,11 \\
2,12\end{array}$ & $\begin{array}{r}89,95 \\
10,40 \\
1,90\end{array}$ \\
\hline $\begin{array}{l}\text { EE }(\%) \\
\text { FDN }(N D F),(\%)\end{array}$ & $\begin{array}{r}1,81 \\
45,43\end{array}$ & $\begin{array}{r}1,55 \\
54,77\end{array}$ & $\begin{array}{r}1,28 \\
64,11\end{array}$ \\
\hline FDA $(A D F),(\%)$ & $\begin{array}{r}27,54 \\
0.52\end{array}$ & $\begin{array}{r}34,33 \\
0,53\end{array}$ & $\begin{array}{r}41,13 \\
0,55\end{array}$ \\
\hline Fósforo (Phosphorus), (\%) & 0,32 & 0,25 & 0,18 \\
\hline Magnésio (Magnesium), (\%) & 0,34 & 0,37 & 0,40 \\
\hline Sódio (Sodium), (\%) & 0,34 & 0,27 & 0,20 \\
\hline Potássio (Potassium), (\%) & 0,91 & 0,78 & 0,63 \\
\hline
\end{tabular}

* Núcleo mineral. Quantidade suprida por kg de produto (núcleo): cálcio, $190 \mathrm{~g}$; fósforo, $73 \mathrm{~g}$; magnésio, $44 \mathrm{~g}$; sódio, $62 \mathrm{~g}$; cloro, $92 \mathrm{~g}$; enxofre, $30 \mathrm{~g}$; zinco, $1350 \mathrm{mg}$; cobre, $340 \mathrm{mg}$; manganês, $940 \mathrm{mg}$; ferro, $1.064 \mathrm{mg}$; cobalto, $3 \mathrm{mg}$; iodo, $16 \mathrm{mg}$; selênio, $18 \mathrm{mg}$; flúor, máximo $730 \mathrm{mg}$.

* Mineral mix. Provided per kilogram of product (premix): calcium, $190 \mathrm{~g}$; phosphorus, 73 g; magnesium, 44 g; sodium, 62 g; chloride, 92 g; sulphur, 30 g; zinc, $1350 \mathrm{mg}$; copper, $340 \mathrm{mg}$; manganese, $940 \mathrm{mg}$; iron, $1064 \mathrm{mg}$; cobalt, $3 \mathrm{mg}$; iodine, $16 \mathrm{mg}$; selenium, $18 \mathrm{mg}$; maximum fluorine, $730 \mathrm{mg}$

concentrado atingiram $25 \mathrm{~kg}$ de PV, mantendo-se o mesmo número de dias no experimento.

Antes do abate, os animais foram pesados para determinação do peso vivo (PV), submetidos a jejum de água e sólidos por 16 horas e novamente pesados, para estimação do peso vivo ao abate (PVA). O abate foi realizado após insensibilização, por meio de descarga elétrica, e sangria, com secção das artérias carótidas e veias jugulares. O sangue foi coletado e pesado para, posteriormente, compor o peso de corpo vazio.

Após esfola, evisceração e desarticulação da cabeça e das extremidades dos membros, as carcaças foram pesadas para obtenção do peso (PCQ) e do rendimento de carcaça quente $(\mathrm{RCQ}=\mathrm{PCQ} / \mathrm{PVA} \times 100) . \mathrm{O}$ trato gastrintestinal (TGI) foi separado e pesado (peso cheio) e, após a retirada do seu conteúdo, realizou-se nova pesagem (peso vazio) para, por diferença entre as duas pesagens, determinar o peso de corpo vazio (PCV) e o rendimento biológico ou verdadeiro $(\mathrm{RB}=\mathrm{PCQ} / \mathrm{PCV} \times 100)$.

As carcaças foram resfriadas a $4^{\circ} \mathrm{C}$ por 24 horas e, ao final desse período, registraram-se o peso da carcaça fria $(\mathrm{PCF})$, a perda de peso por resfriamento $(\mathrm{PPR}=(\mathrm{PCQ}-\mathrm{PCF} /$ PCQ) $x$ 100) e o rendimento de carcaça fria ou comercial $(\mathrm{RCF}=\mathrm{PCF} / \mathrm{PVA} \times 100)$.

As carcaças foram divididas longitudinalmente, na altura da linha média, em dois antíneros, seccionando-se a meia-carcaça direita em cinco regiões anatômicas, segundo Colomer-Rocher et al. (1986) (Figura 1):

- perna: base óssea que abrange a região do ilíaco (ílio), o ísquio, o púbis, as vértebras sacrais, as duas primeiras vértebras coccígeas, o fêmur, a tíbia e o tarso, obtida por corte perpendicular à coluna entre a última vértebra lombar e a primeira sacra;

- lombo: compreende a região das vértebras lombares, obtido perpendicularmente à coluna, entre a $13 \underline{a}$ vértebra dorsal-primeira lombar e última lombar-primeira sacra;

- costelas: envolve as 13 vértebras torácicas, com as costelas correspondentes e o esterno;

- paleta: região que compreende a escápula, o úmero, o rádio, a ulna e o carpo;
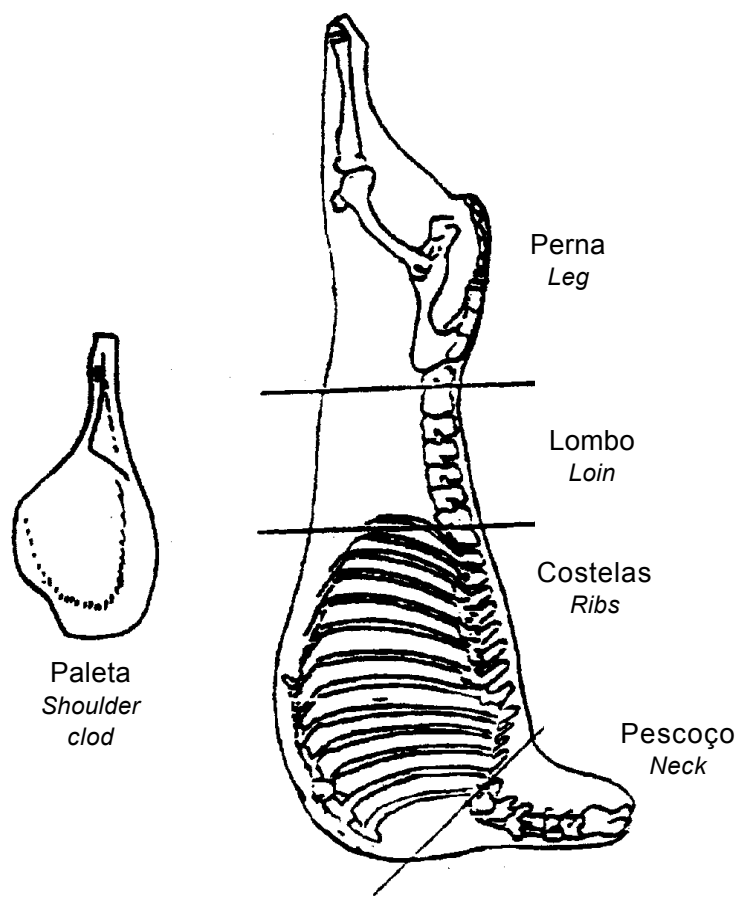

Figura 1 - Cortes cárneos efetuados na meia-carcaça de cordeiros Morada Nova, segundo as regiões anatômicas: perna, lombo, costelas, pescoço e paleta.

Figure 1 - Commercial cuts of the half carcass of Morada Nova lambs according to the anatomical areas: leg, loin, ribs, neck and shoulder clod. 
- pescoço: refere-se às sete vértebras cervicais, obtido por corte oblíquo entre a sétima cervical e a primeira torácica.

Na porção dorsal do músculo Longissimus lumborum, na altura da $12^{\mathrm{a}}$ vértebra torácica (Figura 2), foram efetuadas mensurações para cálculo da área de olho-de-lombo (AOL), conforme Silva Sobrinho et al. (2005). Este músculo foi escolhido por ser de maturação tardia e fácil mensuração, permitindo estimar com confiabilidade o desenvolvimento e o tamanho do tecido muscular. As mensurações constaram de quatro medidas: A - comprimento máximo do músculo; B - profundidade máxima do músculo; C - espessura mínima de gordura de cobertura sobre o músculo; e GR espessura máxima de gordura de cobertura sobre a superfície da $12^{\mathrm{a}}$ costela, a $11 \mathrm{~cm}$ da linha dorso-lombar. A área de olhode-lombo foi calculada utilizando-se a fórmula: $(\mathrm{A} / 2 \times \mathrm{B} / 2) \mathrm{p}$.

Foram realizadas dissecações das pernas, conforme metodologia descrita por Silva Sobrinho et al. (2005), visando determinar as proporções de músculos, ossos e gordura (subcutânea, intermuscular e total), assim como as relações músculo:osso e músculo:gordura e o índice de musculosidade da perna.

As pernas foram retiradas do freezer 24 horas antes da dissecação e descongeladas a $10^{\circ} \mathrm{C}$ em geladeira. Inicialmente, realizou-se uma toalete abaixo das vértebras sacras, retirando-se a musculatura da prega do flanco, a gordura do canal pélvico e a articulação tarsometatarsiana. Em seguida, com auxílio de bisturi, retirou-se a gordura subcutânea. A seguir, os músculos que circundam o fêmur foram retirados na seguinte ordem: Biceps femoris, Semitendinosus, Adductor, Semimembranosus e Quadriceps femoris, e pesados individualmente. Os demais músculos que não

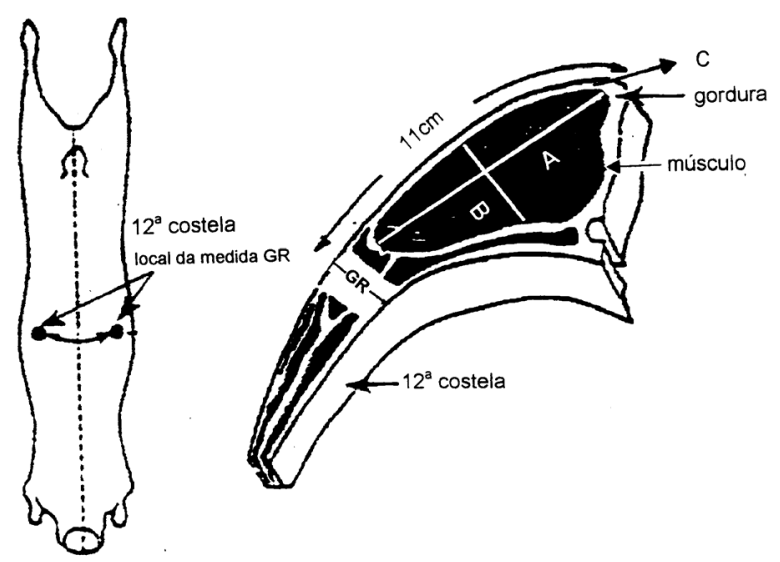

Figura 2 - Mensurações no músculo Longissimus lumborum, na altura da $12^{\text {a }}$ costela: A - largura máxima; B profundidade máxima; $C$ - espessura mínima de gordura; GR - espessura máxima de gordura.

Figure 2 - Measurements in the Longissimus lumborum muscle at the $12^{\text {th }}$ rib: A (maximum width); B (maximum depth); $C$ (minimum fat thickness), and $G R$ (maximum fat thickness). envolvem diretamente o fêmur foram também retirados, porém pesados conjuntamente, para composição do peso total de músculos da perna.

A gordura intermuscular foi retirada e pesada e os ossos (ísquio, ílíaco, púbis, fêmur, tíbia, fíbula e patela), pesados em conjunto. Mediu-se o comprimento do fêmur (cm) e calculou-se o índice de musculosidade da perna (IMP), pela fórmula proposta por Purchas et al. (1991):

$$
I M P=\frac{\sqrt{P 5 M / C F}}{C F},
$$

em que: IMP = índice de musculosidade da perna; P5M = peso dos cinco músculos, em g (Biceps femoris, Semimembranosus, Semitendinosus, Quadriceps femoris e Adductor); $\mathrm{CF}=$ comprimento do fêmur, $\mathrm{em} \mathrm{cm}$.

O delineamento experimental utilizado foi o inteiramente casualizado, com três tratamentos e seis repetições, adotando-se o modelo matemático: $\mathrm{Y}_{\mathrm{ijk}}=\mathrm{m}+\mathrm{T}_{\mathrm{i}}+\mathrm{E}_{\mathrm{ijk}}$, em que: $\mathrm{Y}_{\mathrm{ijk}}=$ valor observado para a característica analisada; $\mathrm{m}=$ média geral; $T_{i}=$ efeito da relação volumoso:concentrado $\mathrm{i}$; e $\mathrm{E}_{\mathrm{ijk}}=$ erro aleatório comum a todas as observações.

Os dados foram submetidos à análise de variância pelo Proc Anova e à análise de regressão pelo Proc Reg do SAS (1999).

\section{Resultados e Discussão}

Os pesos e rendimentos da carcaça são apresentados na Tabela 2. O peso vivo (PV) e o peso vivo ao abate (PVA) foram influenciados $(\mathrm{P}<0,05)$ pela relação volumoso:concentrado na dieta, com maiores valores para os animais que receberam maior porcentagem de concentrado. Garcia et al. (1999) estudaram o efeito do teor de concentrado em dietas isoprotéicas e isoenergéticas para cordeiros em confinamento e não verificaram diferenças sobre o PVA. O fato de as dietas deste estudo não apresentarem composição protéica e energética semelhante deve ter ocasionado essa resposta.

Os pesos de carcaça quente (PCQ) e carcaça fria (PCF) e o peso de corpo vazio (PCV) cresceram linearmente com o aumento da quantidade de concentrado na dieta. Do mesmo modo, os rendimentos de carcaça quente (RCQ) e carcaça fria (RCF) e o rendimento biológico (RB) aumentaram linearmente com o aumento do teor protéico, aportado por dietas com maior proporção de concentrado. Embora todos os animais tenham recebido alimento à vontade, provavelmente a quantidade de proteína ingerida por aqueles que receberam dietas com apenas $30 \%$ de concentrado não 
Tabela 2 - Valores médios e equações de regressão do peso vivo (PV), peso vivo ao abate (PVA), peso de corpo vazio (PCV), pesos de carcaça quente $(P C Q)$ e carcaça fria $(P C F)$, rendimentos de carcaça quente $(R C Q)$ e carcaça fria (RCF), rendimento biológico (RB) e perda por resfriamento (PPR) de cordeiros Morada Nova, de acordo com a relação volumoso:concentrado $(\mathrm{V}: \mathrm{C})$ na dieta

Table 2 - Mean values and regression equations for body weight (BW), slaughter body weight (SBW), empty body weight (EBW), hot carcass (HCW) and cold carcass weights (CCW), hot carcass (HCY), and cold carcass yields (CCY), biological yield (BY) and cooling weight loss (CWL) for Morada Nova lambs fed different dietary ratios of forage and concentrate

\begin{tabular}{|c|c|c|c|c|c|c|}
\hline \multirow[t]{2}{*}{$\begin{array}{l}\text { Variável } \\
\text { Variable }\end{array}$} & \multicolumn{3}{|c|}{$\begin{array}{c}\text { Relação V:C } \\
\text { F:C ratio }\end{array}$} & \multirow[t]{2}{*}{$\begin{array}{l}\text { Regressão } \\
\text { Regression }\end{array}$} & \multirow[t]{2}{*}{$\mathrm{R}^{2}$} & \multirow[t]{2}{*}{$\mathrm{CV}(\%$} \\
\hline & $40: 60$ & $55: 45$ & $70: 30$ & & & \\
\hline PVA $(S B W), \mathrm{kg}$ & 23,70 & 20,01 & 16,32 & $\hat{\mathrm{Y}}=8,9458+0,2458 \mathrm{C} * *$ & 0,90 & 5,26 \\
\hline $\mathrm{PCV}(E B W), \mathrm{kg}$ & 19,83 & 15,99 & 12,15 & $\hat{\mathrm{Y}}=4,4778+0,2559 \mathrm{C} * *$ & 0,93 & 5,67 \\
\hline PCQ $(H C W), \mathrm{kg}$ & 11,07 & 8,75 & 6,44 & $\hat{\mathrm{Y}}=1,8225+0,1540 \mathrm{C} * *$ & 0,94 & 5,60 \\
\hline $\mathrm{RCF}(C C Y), \%$ & 44,91 & 41,23 & 37,54 & $\hat{\mathrm{Y}}=30,1800+0,2454 \mathrm{C}^{* *}$ & 0,80 & 3,83 \\
\hline $\mathrm{RB}(B Y), \%$ & 56,00 & 54,53 & 53,07 & $\hat{\mathrm{Y}}=50,1378+0,0977 * *$ & 0,35 & 3,15 \\
\hline PPR (CWL), \% & 4,29 & 4,90 & 5,50 & $\mathrm{Y}=4,89 \mathrm{~ns}$ & - & 26,82 \\
\hline
\end{tabular}

** Significativo a $1 \%$ de probabilidade pelo teste $\mathrm{t}$ (Significant at $1 \%$ of probability by $t$ test).

ns Não-significativo (Not significant).

$\mathrm{R}^{2}$ e CV = coeficientes de determinação e variação, respectivamente $\left(R^{2}\right.$ and CV = coefficients of determination and variation, respectively).

atendeu à demanda exigida para o crescimento muscular nesta fase, fazendo com que apresentassem baixo ganho de peso (38 g/dia) em relação aos dos tratamentos com maiores quantidades de concentrado ( 107 e $172 \mathrm{~g} / \mathrm{dia}$, para 45 e $60 \%$ de concentrado, respectivamente).

A perda de peso por resfriamento (PPR) consiste na perda de umidade da carcaça na câmara fria e nas reações químicas no músculo durante o processo de resfriamento (Kirton, 1986). Silva Sobrinho et al. (2005) afirmam que essas perdas são maiores em carcaças com menor gordura de cobertura. Neste estudo, não ocorreram diferenças $(\mathrm{P}>0,05)$ entre os tratamentos, em razão da pequena quantidade de gordura de cobertura nas carcaças e do elevado coeficiente de variação registrado para esta variável. Verificou-se média de 4,98\%, superior à observada por Carneiro et al. (2001), que, ao estudarem as características da carcaça de cordeiros Texel, encontraram valor médio de $2,67 \%$ para a quebra por resfriamento.

Na Tabela 3 são descritos os pesos da meia-carcaça e dos cortes comerciais, observando-se crescimento linear para todos os cortes de acordo com o aumento de concentrado na dieta. Os pesos da perna, do lombo, da paleta e das costelas dos animais alimentados com a dieta com maior quantidade de concentrado foram superiores $(\mathrm{P}<0,01)$ aos obtidos nos demais tratamentos, corroborando a constatação de que o pesos da meia-carcaça variaram na mesma proporção.

A participação proporcional dos cortes em relação ao peso da meia-carcaça apresentou tendência diferente à observada para peso absoluto (Tabela 4), com diferenças
$(\mathrm{P}<0,05)$ apenas para o lombo. As maiores porcentagens foram verificadas nos animais sob dietas com maior teor de concentrado.

As porcentagens da paleta e da perna não foram influenciadas $(\mathrm{P}>0,05)$ pelos teores de concentrado na dieta, sendo considerados, juntamente com o lombo, os cortes de maior valor comercial da carcaça. Estes resultados confirmam a lei da harmonia anatômica (Boccard, citado por Siqueira, 2000), a partir da verificação de que o rendimento dos cortes, mesmo para pesos de abate diferentes, não sofreu grandes variações.

Macedo et al. (2000), estudando cordeiros Corriedale, Bergamácia x Corriedale e Hampshire Down x Corriedale em confinamento, submetidos a dietas com $18 \%$ de proteína, encontraram valores de $32,91 \%$ para rendimento da perna, $18,86 \%$ para a paleta, $9,88 \%$ para o lombo e $6,00 \%$ para o pescoço. Ribeiro et al. (2001) avaliaram características quantitativas da carcaça de cordeiros Ile de France inteiros abatidos aos 12 meses de idade e observaram rendimentos de 10,$82 ; 18,33$ e $33,35 \%$ para pescoço, paleta e perna, respectivamente.

Os pesos da perna e de seus componentes (Tabela 5) cresceram linearmente $(\mathrm{P}<0,01)$ com o aumento do concentrado, à exceção do comprimento do fêmur, visto que os animais apresentavam alturas corporais semelhantes, variando apenas na compacidade e no desenvolvimento muscular. Os pesos médios dos músculos que circundam o fêmur variaram na mesma proporção do peso total dos músculos da perna. 
Tabela 3 - Valores médios e equações de regressão dos pesos da meia-carcaça (PMC) e dos cortes comerciais (paleta, perna, lombo, costelas e pescoço) de cordeiros Morada Nova, de acordo com a relação volumoso:concentrado(V:C) na dieta

Table 3 - Mean values and regression equations for the weights of the half carcass (WHC) and commercial cuts (shoulder clod, leg, loin, ribs and neck), of Morada Nova lambs fed different dietary ratios of forage and concentrate

\begin{tabular}{|c|c|c|c|c|c|c|}
\hline \multirow[t]{2}{*}{$\begin{array}{l}\text { Variável } \\
\text { Variable }\end{array}$} & \multicolumn{3}{|c|}{$\begin{array}{c}\text { Relação V:C } \\
F: C \text { ratio }\end{array}$} & \multirow[t]{2}{*}{$\begin{array}{l}\text { Regressão } \\
\text { Regression }\end{array}$} & \multirow[t]{2}{*}{$\mathrm{R}^{2}$} & \multirow[t]{2}{*}{ CV (\%) } \\
\hline & $40: 60$ & $55: 45$ & $70: 30$ & & & \\
\hline $\mathrm{PMC}(W H C)$ & 5,29 & 4,17 & 3,04 & $\hat{\mathrm{Y}}=6,4218+1,1272 \mathrm{C} * *$ & 0,95 & 5,29 \\
\hline Peso da paleta (Pallete weight) & 1,06 & 0,81 & 0,60 & $\hat{\mathrm{Y}}=1,2368+0,2118 \mathrm{C} * *$ & 0,93 & 6,26 \\
\hline Peso da perna (Leg weight) & 1,75 & 1,40 & 1,05 & $\hat{\mathrm{Y}}=2,1040+0,3501 \mathrm{C}^{* *}$ & 0,93 & 5,79 \\
\hline Peso do lombo (Loin weight) & 0,67 & 0,50 & 0,33 & $\hat{\mathrm{Y}}=0,8413+0,1712 \mathrm{C}^{* *}$ & 0,90 & 10,18 \\
\hline Peso das costelas (Ribs weight) & 1,33 & 1,04 & 0,75 & $\hat{\mathrm{Y}}=1,6247+0,2932 \mathrm{C}^{* *}$ & 0,88 & 8,83 \\
\hline Peso do pescoço (Neck weight) & 0,51 & 0,41 & 0,31 & $\hat{\mathrm{Y}}=0,6150+0,1010 \mathrm{C}^{* *}$ & 0,54 & 19,46 \\
\hline
\end{tabular}

** Significativo a $1 \%$ de probabilidade pelo teste $\mathrm{t}$ (Significant at $1 \%$ of probability, by $t$ test).

$\mathrm{R}^{2}$ e CV = coeficientes de determinação e variação, respectivamente $\left(R^{2}\right.$ and $C V=$ coefficients of determination and variation, respectively).

Tabela 4 - Rendimentos dos cortes comerciais (\%) na meia-carcaça de cordeiros Morada Nova, de acordo com a relação volumoso:concentrado $(\mathrm{V}: \mathrm{C})$ na dieta

Table 4 - $\quad$ Commercial cuts dressing (\%) of half carcass of Morada Nova lambs fed different dietary ratios of forage and concentrate

\begin{tabular}{|c|c|c|c|c|c|c|}
\hline \multirow[t]{2}{*}{$\begin{array}{l}\text { Variável } \\
\text { Variable }\end{array}$} & \multicolumn{3}{|c|}{$\begin{array}{c}\text { Relação V:C } \\
F: C \text { ratio }\end{array}$} & \multirow[t]{2}{*}{$\begin{array}{l}\text { Regressão } \\
\text { Regression }\end{array}$} & \multirow[t]{2}{*}{$\mathrm{R}^{2}$} & \multirow[t]{2}{*}{ CV $(\%)$} \\
\hline & $40: 60$ & $55: 45$ & $70: 30$ & & & \\
\hline Paleta (Shoulder clod) & 19,34 & 19,58 & 19,82 & $\hat{\mathrm{Y}}=19,5794 \mathrm{~ns}$ & & 5,67 \\
\hline Perna (Leg) & 33,06 & 33,88 & 34,70 & $\hat{\mathrm{Y}}=33,8765 \mathrm{~ns}$ & - & 4,96 \\
\hline Lombo (Loin) & 12,73 & 11,81 & 10,89 & $\hat{\mathrm{Y}}=13,6536+0,9224 \mathrm{C}^{* *}$ & 0,40 & 8,22 \\
\hline Costelas (Ribs) & 25,18 & 24,82 & 24,46 & $\hat{\mathrm{Y}}=24,8189 \mathrm{~ns}$ & - & 4,62 \\
\hline Pescoço (Neck) & 9,70 & 9,92 & 10,14 & $\hat{\mathrm{Y}}=9,9165^{\mathrm{ns}}$ & - & 15,00 \\
\hline
\end{tabular}

** Significativo a $1 \%$ de probabilidade pelo teste $\mathrm{t}$ (Significant at $1 \%$ of probability, by $t$ test).

ns Não-significativo (Not significant).

$\mathrm{R}^{2}$ e CV = coeficientes de determinação e variação, respectivamente $\left(R^{2}\right.$ and CV = coefficients of determination and variation, respectively).

A quantidade de osso na perna de cordeiros alimentados com dietas contendo teores crescentes de concentrado não aumentou na mesma proporção que a quantidade de músculo, resultando em crescimento linear $(\mathrm{P}<0,05)$ da relação músculo:osso com o aumento do teor de concentrado na dieta. A relação músculo:gordura decresceu linearmente $(\mathrm{P}<0,05)$ de acordo com o teor de concentrado na dieta. Ressalta-se, no entanto, que, embora as pernas de todos os cordeiros tenham apresentado quantidades reduzidas de gordura, a relação músculo:gordura foi maior naqueles que receberam menor quantidade de concentrado na dieta.

O índice de musculosidade da perna (IMP), indicador da quantidade de músculo neste corte, apresentou pequena variação $(\mathrm{P}<0,01)$ com a elevação da proporção de concentrado.

Na Tabela 6 , constam as porcentagens dos diferentes tecidos (músculo, osso e gordura) em relação ao peso da perna. Apesar do maior peso de abate e do maior peso da perna dos animais que receberam a dieta com maior proporção de concentrado, a porcentagem de músculo não diferiu $(\mathrm{P}>0,05)$ entre os tratamentos. Rosa et al. (2000) estudaram a composição tecidual da carcaça de cordeiros Texel alimentados com dietas distintas e abatidos com diferentes pesos e concluíram que a proporção de músculo na perna não foi influenciada pela dieta ou pelo peso de abate.

Silva Sobrinho et al. (2002), avaliando o efeito de diferentes relações volumoso:concentrado na composição tecidual da perna de cordeiros confinados, observaram valores médios de $70,69 \%$ de músculo, $14,65 \%$ de osso e $14,62 \%$ de gordura. De acordo com Figueiró \& Benavides (1990), conforme o peso do animal aumenta, observa-se variação nas proporções de osso, músculo e gordura, com diminuição da porcentagem de músculo e aumento na de gordura. Esse efeito foi observado neste experimento com relação ao teor de gordura, pois o peso de abate foi maior na dieta com maior proporção de concentrado, assim como a proporção de gordura da perna.

As proporções de gordura total e subcutânea foram maiores $(\mathrm{P}<0,01)$ nos teores mais elevados de concentrado. Rosa et al. (2000) observaram comportamento semelhante, 
Tabela 5 - Componentes da perna de cordeiros Morada Nova, de acordo com a relação volumoso:concentrado (V:C) na dieta Table 5 - Components of the leg of Morada Nova lambs fed different dietary ratios of forage and concentrate

\begin{tabular}{|c|c|c|c|c|c|c|}
\hline \multirow[t]{2}{*}{$\begin{array}{l}\text { Componente } \\
\text { Component }\end{array}$} & \multicolumn{3}{|c|}{$\begin{array}{c}\text { Relação V:C } \\
F: C \text { ratio }\end{array}$} & \multirow[t]{2}{*}{$\begin{array}{l}\text { Regressão } \\
\text { Regression }\end{array}$} & \multirow[t]{2}{*}{$\mathrm{R}^{2}$} & \multirow[t]{2}{*}{$\overline{C V}(\%)$} \\
\hline & $40: 60$ & $55: 45$ & $70: 30$ & & & \\
\hline P5M（g) & 689,12 & 561,29 & 433,46 & $\hat{\mathrm{Y}}=177,8019+8,5219 \mathrm{C} * *$ & 0,94 & 5,14 \\
\hline Músculo total (g) (Total muscle) & 1115,00 & 894,03 & 672,96 & $\hat{\mathrm{Y}}=230,8225+14,7379 \mathrm{C} * *$ & 0,95 & 4,89 \\
\hline Gordura subcutânea (Sub-cutaneous fat), $\mathrm{g}$ & 122,46 & 82,05 & 41,64 & $\hat{\mathrm{Y}}=-39,1731+2,6938 \mathrm{C} * *$ & 0,86 & 17,00 \\
\hline Comprimento do fêmur $(\mathrm{cm})$ (Femur lenght) & 16,29 & 16,01 & 15,73 & $\hat{\mathrm{Y}}=16,01 \mathrm{~ns}$ & - & 6,01 \\
\hline Osso total (g) (Total bone) & 282,86 & 256,22 & 229,57 & $\hat{\mathrm{Y}}=176,2858+1,7763 \mathrm{C}^{* *}$ & 0,57 & 7,87 \\
\hline Outros tecidos ${ }^{2}$ (g) (Other tissues) & 52,20 & 33,89 & 15,58 & $\hat{\mathrm{Y}}=-21,0408+1,2206 \mathrm{C} * *$ & 0,87 & 18,14 \\
\hline Relação músculo:osso (Muscle:bone ratio) & 3,97 & 3,47 & 2,96 & $\hat{\mathrm{Y}}=1,9597+0,0335 \mathrm{C}^{* *}$ & 0,79 & 6,49 \\
\hline Relação músculo:gordura (Muscle:fat ratio) & 5,63 & 7,23 & 8,82 & $\hat{\mathrm{Y}}=12,0072-0,1062 \mathrm{C} * *$ & 0,78 & 10,07 \\
\hline
\end{tabular}

${ }_{1}^{1}$ P5M = Peso dos cinco músculos (Biceps femoris, Quadriceps femoris, Semimembranosus, Semitendinosus e Adductor).

1 P5M = weight of five muscle (Biceps femoris, Quadriceps femoris, Semimembranosus, Semitendinosus and Adductor).

2 Tendões, cartilagens e ligamentos (Tendons, cartilages and ligaments).

3 ÍMP = índice de musculosidade da perna (Leg muscularity index)

** Significativo a $1 \%$ de probabilidade pelo teste $\mathrm{t}$ (Significant at $1 \%$ of probability, by $t$ test).

ns Não-significativo (Not significant).

$\mathrm{R}^{2}$ e CV = coeficientes de determinação e variação, respectivamente $\left(R^{2}\right.$ and $C V=$ coefficients of determination and variation, respectively).

Tabela 6 - Porcentagens de músculo, osso e gordura na perna de cordeiros Morada Nova, de acordo com a relação volumoso:concentrado( $\mathrm{V}: \mathrm{C})$ na dieta

Table 6 - Percentage of muscle, bone and fat in the leg of Morada Nova lambs fed different dietary ratios of forage and concentrate

\begin{tabular}{|c|c|c|c|c|c|c|}
\hline \multirow{2}{*}{$\begin{array}{l}\text { Componente } \\
\text { Component }\end{array}$} & \multicolumn{3}{|c|}{$\begin{array}{c}\text { Relação V:C } \\
\text { F:C ratio }\end{array}$} & \multirow{2}{*}{$\begin{array}{l}\text { Regressão } \\
\text { Regression }\end{array}$} & \multirow[t]{2}{*}{$\mathrm{R}^{2}$} & \multirow[t]{2}{*}{$\mathrm{CV}(\%)$} \\
\hline & $40: 60$ & $55: 45$ & $70: 30$ & & & \\
\hline Total de ossos (Total bone) & 16,94 & 19,92 & 22,89 & $\hat{\mathrm{Y}}=28,8325-0,1982 \mathrm{C} * *$ & 0,84 & 5,56 \\
\hline Gordura subcutânea (Sub-cutaneous fat) & 7,42 & 5,98 & 4,55 & $\mathrm{Y}=1,6828+0,0956 \mathrm{C}^{* *}$ & 0,68 & 14,25 \\
\hline Gordura intermuscular (Inter-muscle fat) & 4,71 & 3,82 & 2,93 & $\hat{\mathrm{Y}}=1,1442+0,0595 \mathrm{C} * *$ & 0,75 & 11,55 \\
\hline
\end{tabular}

1 Tendões, cartilagens e ligamentos (Tendons, cartilages and ligaments).

** Significativo a $1 \%$ de probabilidade pelo teste $\mathrm{t}$ (Significant at $1 \%$ of probability, by $t$ test).

ns Não-significativo (Not significant).

$\mathrm{R}^{2} \mathrm{e} C V=$ coeficientes de determinação e variação, respectivamente $\left(R^{2}\right.$ and $C V=$ coefficients of determination and variation, respectively).

com maiores proporções de gordura nos animais mais pesados e alimentados com dietas mais energéticas. Callow (1948) demonstrou que a restrição afetou negativamente a porcentagem de gordura depositada na carcaça de caprinos, espécie com certa similaridade aos ovinos deslanados com relação à deposição de gordura na carcaça, notando-se que ambas, caracteristicamente, depositam gordura primeiramente na cavidade abdominal e mais tardiamente na carcaça. A gordura intermuscular nos animais diferiu $(\mathrm{P}<0,01)$ entre os tratamentos, com menores valores naqueles que receberam menos concentrado.

Garcia et al. (2000), trabalhando com ovinos de diferentes genótipos abatidos aos 15 e $25 \mathrm{~kg}$, registraram valores médios para proporção de osso de 18,19 e 15,60\% e, para proporção de gordura, de 4,99 e 7,18\%, respectivamente. Este comportamento também foi observado neste experimento, ou seja, conforme o peso dos animais aumentou, a proporção de osso diminuiu e a de gordura aumentou.

Houve aumento $(\mathrm{P}<0,01)$ na proporção de osso nos animais alimentados com maiores proporções de volumoso. Ressalta-se que a restrição alimentar qualitativa deste grupo ocasionou menores coberturas musculares e ganho de peso de apenas $38 \mathrm{~g} /$ dia e que o tecido ósseo tem crescimento mais precoce em relação aos outros tecidos, particularmente os ossos da perna e da paleta.

As medidas objetivas realizadas no músculo Longissimus lumborum encontram-se na Tabela 7. O comprimento máximo do músculo não foi influenciado $(\mathrm{P}>0,05)$ pelos 
Tabela 7 - Mensurações no músculo Longissimus lumborum de cordeiros Morada Nova submetidos a dietas com diferentes relações volumoso:concentrado $(\mathrm{V}: \mathrm{C})$

Table 7 - Measurements taken in the Longissimus lumborum muscle of Morada Nova lambs fed different dietary ratios of forage and concentrate

\begin{tabular}{|c|c|c|c|c|c|c|}
\hline \multirow{2}{*}{$\begin{array}{l}\text { Parâmetro } \\
\text { Parameter }\end{array}$} & \multicolumn{3}{|c|}{$\begin{array}{c}\text { Relação V:C } \\
\text { F:C ratio }\end{array}$} & \multirow{2}{*}{$\begin{array}{l}\text { Regressão } \\
\text { Regression }\end{array}$} & \multirow[t]{2}{*}{$\mathrm{R}^{2}$} & \multirow[t]{2}{*}{ CV $(\%)$} \\
\hline & $40: 60$ & $55: 45$ & $70: 30$ & & & \\
\hline Medida (Measurement) A $(\mathrm{cm})$ & 4,54 & 4,33 & 4,12 & $\hat{\mathrm{Y}}=4,3294 \mathrm{~ns}$ & - & 8,90 \\
\hline Medida (Measurement) B (cm) & 2,23 & 1,84 & 1,46 & $\hat{\mathrm{Y}}=0,6839+0,0258 \mathrm{C} * *$ & 0,70 & 11,97 \\
\hline Medida (Measurement) $\mathrm{C}(\mathrm{cm})$ & 0,11 & 0,10 & 0,09 & $\hat{\mathrm{Y}}=0,0956 \mathrm{~ns}$ & - & 38,44 \\
\hline Medida (Measurement) GR $(\mathrm{cm})$ & 0,22 & 0,17 & 0,12 & $\hat{\mathrm{Y}}=0,0136+0,0035 \mathrm{C} * *$ & 0,46 & 28,59 \\
\hline $\mathrm{AOL}\left(\mathrm{cm}^{2}\right)$ & 7,89 & 6,30 & 4,71 & $\hat{\mathrm{Y}}=1,5311+0,1060 \mathrm{C}^{* *}$ & 0,76 & 12,24 \\
\hline
\end{tabular}

Medida (Measurement) A = comprimento máximo do músculo (maximum length of the muscle); Medida (Measurement) $\mathrm{B}=$ profundidade máxima do músculo (maximum depth of the muscle); Medida (Measurement) $\mathrm{C}=$ espessura mínima de gordura sobre o músculo (minimum muscle fat thickness); Medida (Measurement) GR = espessura máxima de gordura sobre o músculo (maximum muscle fat thickness) e AOL = área de olho-de-lombo (loin eye area).

** Significativo a $1 \%$ de probabilidade pelo teste $\mathrm{t}$ (Significant at $1 \%$ of probability, by $t$ test)

ns Não-significativo (Not significant).

$\mathrm{R}^{2}$ e CV = coeficientes de determinação e variação, respectivamente $\left(R^{2}\right.$ and CV = coefficients of determination and variation, respectively).

crescentes teores de concentrado, com valor médio de $4,33 \mathrm{~cm}$. Dietas com maiores proporções de volumoso propiciaram menor profundidade do músculo.

Os diferentes teores de concentrado não influenciaram $(\mathrm{P}>0,05)$ a espessura mínima de gordura, corroborando os resultados descritos por Zundt et al. (2002), que avaliaram crescentes teores de proteína $(12,16,20$ e $24 \%)$ e não encontraram efeito $(\mathrm{P}>0,05)$ sobre essa característica. A espessura máxima de gordura sobre o Longissimus lumborum (Medida GR) aumentou linearmente, como resultado dos teores crescentes de concentrado na dieta.

Os crescentes teores de concentrado aumentaram $(\mathrm{P}<0,01)$ a área de olho-de-lombo ( $\mathrm{AOL})$, que foi maior $\left(7,89 \mathrm{~cm}^{2}\right)$ nos animais alimentados com a dieta com maior proporção de concentrado. Quando comparados a animais selecionados para produção de carne e abatidos com pesos mais elevados, esses resultados foram inferiores, pois a AOL é uma medida que indica a quantidade de carne comercializável. Zundt et al. (2002) testaram crescentes teores protéicos $(12,16,20$ e 24\%) na dieta de cordeiros mestiços Texel, Bergamácia e Corriedale em confinamento, abatidos aos $34 \mathrm{~kg}$ de $\mathrm{PV}$, e registraram valor médio de $13,84 \mathrm{~cm}^{2}$.

Macedo et al. (2000), em estudo com cordeiros confinados Corriedale, Bergamácia x Corriedale e Hampshire Down x Corriedale submetidos a dietas com $18 \%$ de proteína, encontraram área de olho-de-lombo de 10,21 $\mathrm{cm}^{2}$. Em estudo para avaliar os efeitos da substituição do milho moído pelo resíduo de panificação (biscoito) em dietas para cordeiros cruzas Ile de France e Ideal, Garcia (1998) não encontrou influência $(\mathrm{P}>0,05)$ das substituições sobre a área de olho-de-lombo, com média de $9,92 \mathrm{~cm}^{2}$.

Silva Sobrinho et al. (2005), em estudo com ovinos de diferentes genótipos selecionados para produção de carne, observaram comprimento e profundidade máxima do músculo de 5,69 e 2,78 cm, espessuras mínima e máxima de gordura de 0,19 e $0,50 \mathrm{~cm}$ e área de olho-de-lombo de $12,47 \mathrm{~cm}^{2}$.

\section{Conclusões}

O maior teor de concentrado na dieta propiciou maior peso ao abate e maiores pesos de carcaça quente e fria.

O aumento de 30 para $60 \%$ de concentrado na dieta elevou os rendimentos de carcaça quente e carcaça fria, assim como o rendimento biológico.

Os crescentes teores de concentrado na dieta não alteraram a porcentagem de músculo na perna, mas proporcionaram maior deposição de gorduras subcutânea, intermuscular e total e maior área de olho-de-lombo.

\section{Literatura Citada}

AGRICULTURAL AND FOOD RESEARCH COUNCIL - AFRC. Necesidades energéticas y proteicas de los rumiantes. Zaragoza: Acribia, 1993. $175 \mathrm{p}$.

CALLOW, E.H. Comparative studies of meat. 2. The changes in the carcass during growth and fattening and their relation to the chemical composition of fatty and muscular tissues. Journal of Agricultural Science, v.38, n.2, p.174-198, 1948.

CARNEIRO, R.M.; PIRES, C.C.; MÜLLER, L. et al. Características da carcaça de cordeiros de parto simples e duplo alimentados em confinamento. In: REUNIÃO ANUAL DA SOCIEDADE BRASILEIRA DE ZOOTECNIA, 38., 2001, Piracicaba. Anais... Piracicaba: Sociedade Brasileira de Zootecnia, 2001. p.1333-1334.

COLOMER-ROCHER, F. Los criterios de calidad de la canal: sus implicaciones biológicas. In: CURSO INTERNACIONAL SOBRE LA PRODUCCIÓN DE OVINO DE CARNE, 1986, Zaragoza. Papers... Zaragoza: 1986. v.2, 66p.

FIGUEIRÓ, P.R.P.; BENAVIDES, M.V. Produção de carne ovina. In: SIMPÓSIO DA REUNIÃO DA SOCIEDADE BRASILEIRA DE ZOOTECNIA, 27., 1990, Piracicaba. Anais... Piracicaba: Sociedade Brasileira de Zootecnia, 1990. p.16-31. 
GARCIA, C.A. Avaliação do resíduo de panificação "biscoito" na alimentação de ovinos e nas características quantitativas e qualitativas da carcaça. Jaboticabal: Universidade Estadual Paulista, 1998. 79p. Dissertação (Mestrado em Zootecnia) Universidade Estadual Paulista, 1998.

GARCIA, C.A.; SILVA SOBRINHO, A.G.; GASTALDI, K.A. Influência das diferentes relações volumoso:concentrado e pesos de abate de cordeiros confinados. 1. Rendimentos dos cortes e características das carcaças. In: REUNIÃO ANUAL DA SOCIEDADE BRASILEIRA DE ZOOTECNIA, 36., 1999, Porto Alegre. Anais... São Paulo: Gmosis, CD-ROM. Qualidade de Produtos de Origem Animal. QUA-18.

GARCIA, I.F.F.; PÉREZ, J.R.O.; OLIVEIRA, M.V.M. et al. Características de carcaça de cordeiros Texel x Bergamácia, Texel x Santa Inês e Santa Inês puros, terminados em confinamento, com casca de café como parte da dieta. Revista Brasileira de Zootecnia, v.29, n.1, p.253-260, 2000.

KEMPSTER, A.J.; CROSTON, D.; GUY, D.R. et al. Growth and carcass characteristics of crossbred lams by tem sire breeds, compared at the same estimarted carcass subcutaneous fat proportion. Animal Production, v.44, n.1, p.83-98, 1987.

KIRTON, A.H. Animal Industries Workshop Lincoln College, Technical Handbook (lamb growth - carcass composition). 2.ed. Canterbury: Lincoln College, 1986. p.25-31.

MACEDO, F.A.F.; SIQUEIRA, E.R.; MARTINS, E.N. et al. Qualidade de carcaças de cordeiros Corriedale puros e mestiços terminados em pastagem e confinamento. Revista Brasileira de Zootecnia, v.29, n.5, p.1520-1527, 2000

OLIVEIRA, A.A.P.; LIMA, V.P.M.S. Aspectos econômicos da caprino-ovinocultura tropical brasileira. In: SEMANA DA CAPRINOCULTURA E DA OVINOCULTURA TROPICAL BRASILEIRA, 1., 1994, Sobral. Anais... Sobral: Embrapa Caprinos, 1994. p.7-46.

PURCHAS, R.W.; DAVIES, A.S.; ABDULLAH, A.Y. An objective measure of muscularity: changes with animal growth and differences between genetic lives of Southdown sheep. Meat Science, v.30, n.1, p.81-94, 1991.

RIBEIRO, E.L.A.; ROCHA, M.A.; MIZUBUTI, I.Y. et al. Carcaça de borregos Ile de France inteiros ou castrados e Hampshire Down castrados abatidos aos doze meses de idade. Ciência Rural, v.31, n.3, p.479-482, 2001.

ROSA, G.T.; PIRES, C.C.; MOTTA, O.S. et al. Composição tecidual dos cortes da carcaça de cordeiros (as) em diferentes métodos de alimentação e pesos de abate. In: REUNIÃO ANUAL DA SOCIEDADE BRASILEIRA DE ZOOTECNIA, 37., 2000, Viçosa, MG. Anais... Viçosa, MG: Sociedade Brasileira de Zootecnia/Gmosis. CD-ROM. Manejo e Reprodução. MAN-1076.

STATISTICAL ANALYSIS SYSTEMS - SAS. User's guide. Versão 8.0. North Carolina: 1999.

SILVA SOBRINHO, A.G.; MACHADO, M.R.F.; GASTALDI, K.A. et al. Efeitos da relação volumoso:concentrado e do peso ao abate sobre os componentes da perna de cordeiros Ile de France $x$ Ideal confinados. Revista Brasileira de Zootecnia, v.31, n.2, p.1017-1023, 2002 .

SILVA SOBRINHO, A.G.; PURCHAS, R.W.; KADIM, I.T. et al. Musculosidade e composição da perna de ovinos de diferentes genótipos e idades de abate. Pesquisa Agropecuária Brasileira v.40, n.11, p.1129-1134, 2005.

SILVA SOBRINHO, A.G.; MACHADO, M.R.F.; GASTALDI, K.A et al. Efeitos da relação volumoso:concentrado e do peso ao abate sobre a composição tecidual da perna de cordeiros confinados. In: REUNIÃO ANUAL DA SOCIEDADE BRASILEIRA DE ZOOTECNIA, 38., 2001, Piracicaba. Anais... Piracicaba: Sociedade Brasileira de Zootecnia, 2001. p.957-959

SILVA, A.M.A.; RODRIGUES, L.; RESENDE, K.T. et al. Avaliação da seletividade de ovinos lanados e deslanados em dietas com diferentes níveis de concentrado:volumoso. In: REUNIÃO ANUAL DA SOCIEDADE BRASILEIRA DE ZOOTECNIA, 37. 2000, Viçosa, MG. Anais... Viçosa, MG: Sociedade Brasileira de Zootecnia, 2000. p.339.

SILVA, A.M.A.; SILVA SOBRINHO, A.G.; TRINDADE, I.A.C.M. et al. Net requirements of protein and energy for maintenance of wool and hair lambs in a tropical region. Small Ruminant Research, v.49, n.2, p.165-171, 2003.

SIQUEIRA, E.R. Sistemas de confinamento de ovinos para corte do Sudeste do Brasil. In: SIMPÓSIO INTERNACIONAL SOBRE CAPRINOS E OVINOS DE CORTE, 1., 2000, João Pessoa Anais... João Pessoa: EMEPA, 2000. p.107-117.

ZUNDT, M.; MACEDO, F.A.F; MARTINS, E.N. et al, Desempenho de cordeiros alimentados com diferentes níveis protéicos. 1. Características de carcaças de cordeiros terminados em confinamento, com dietas contendo diferentes níveis protéicos. Revista Brasileira de Zootecnia, v. 31 , n.3, p.1307-1314, 2002. 